\title{
APROXIMAÇÕES ENTRE FOUCAULT E BENJAMIN: UMA ONTOLOGIA PARA O PRESENTE E O TEMPO DO AGORA (JETZTZEIT)
}

Kácia Natalia de Barros Sousa Lima

\begin{abstract}
RESUMO
A crítica à institucionalização do saber em Walter Benjamin e Michel Foucault apontam, na tradição filosófica, a sujeição do indivíduo e seu afastamento do tempo do agora. Tanto no ensaio Os intelectuais e o poder de Foucault como $n$ 'A vida dos Estudantes de Benjamin esse diagnóstico é feito a partir do processo de profissionalização. Ambos os autores discutem as formas pelas quais os discursos são proferidos por estudantes e intelectuais como condição de pensar o seu presente.
\end{abstract}

Palavras-chave: Institucionalização. História do Saber. Tempo do agora.

\section{THE INSTITUTIONALIZATION OF KNOWLEDGE AND THE REMOVAL OF THE SUBJECT'S TIME NOW: SIMILARITIES BETWEEN THE WRITINGS OF WALTER BENJAMIN AND MICHEL FOUCAULT}

\begin{abstract}
This text is born from the attempt to bring the considerations made by philosophers Walter Benjamin and Michel Foucault on the institutionalization of knowledge and the reflection of this fact in the ways of subjection of individuals and the removal of the thought of the time now. For thinkers such institutionalization results in the removal of individuals to be professionalized in the design of Benjamin in the assay Life of Students, or tamed and domesticated, Foucault's analysis in the text Intellectuals and Power, is far from thinking his present, their daily lives. Both authors begin with the attempt to present in their texts cited, in our study, the proposed possibility through critical of thinking the time "now". Our reflections lead us to think about the emergence of speeches to be appropriate and delivered by students and today's intellectuals in an attempt to promote new forms of life able to resume for themselves
\end{abstract}


Todos os tipos de categorias profissionais serão convidados a exercer funções policiais cada vez mais precisas

(Foucault)

O desempenho social do homem comum serve para recalcar as aspirações originais e autenticas do homem interior. O sentimento de dever é calculado, postiço e distorcido.

Walter Benjamin

Transformar o estado imanente de plenitude de forma pura em estado absoluto, torna-lo visível e soberano no presente - eis a tarefa histórica.

Walter Benjamin (A vida dos Estudantes)

É possível começar a pensar, a partir do tempo do agora (jetztzeit) o lugar e a tarefa do estudante no ensaio A Vida dos Estudantes de Walter Benjamin (18921940)? Em que medida estaria relacionada tal investigação à concepção de história do saber do filósofo de Poitiers, Michel Foucault (1926-1984)? Há uma concepção da história que acreditando no progresso, perde qualquer rigor no presente, o tempo de agora. É a partir deste tempo que podemos começar a pensar qual seja o lugar e a tarefa do estudante a partir do texto de Walter Benjamin, segundo esse a "concepção de história que, confinando na eternidade do tempo, só distingue o ritmo dos homens e das épocas que correm rápida ou lentamente na esteira do progresso.". Só é possível pensar a vida do estudante se for a partir da totalidade em que vivemos, o sistema, e o mercado mundial, que possuem sua forma cada vez mais desconfigurada, nas palavras do autor: "resta apenas libertar o futuro de sua forma desfigurada, através de um ato de conhecimento. somente para isso serve a crítica $^{2} . "$, ou seja, para Walter Benjamin é necessário uma crítica verdadeira para libertar o vindouro de sua forma sem configuração, reconhecendo-o no presente, e é este o papel da verdadeira crítica.

Desse ponto de vista segue-se Michel Foucault que se opõem as diferentes concepções de vertente hegeliana, da filosofia da história, ou seja, através do seu método arqueológico ${ }^{3}$ rompeu com a história linear, progressiva e totalizante de uma

\footnotetext{
BENJAMIN, 1986, p. 151.

Idem, ibidem, 1986, p. 151.

3 "A arqueologia não se ocupa dos conhecimentos descritos segundo seu progresso em direção a uma objetividade, que encontraria sua expressão no presente da ciência, mas da episteme, em que os conhecimentos são abordados sem se referir ao seu valor racional ou a sua objetividade. A 
razão, quer dizer, é diretamente oposta, o filósofo de Poitiers não pensa uma história em termos de consciência, mas pensa uma história a partir de uma concepção da história do saber.

Mas como pode o estudante, diante desta realidade espetacularizada, da "economização" da vida, elaborar uma verdadeira crítica? Segundo Benjamin

medir a vida estudantil com a ideia de ciência não significa, de modo algum, panlogismo ou intelectualismo - como se possa temer -, mas é uma crítica legítima, já que na maioria das vezes a ciência é evocada como baluarte dos estudantes ${ }^{4}$.

Outrossim Walter Benjamin pensa a vida do estudante abordada mediante a questão da unidade consciente, e para tanto, é necessário pensar a relação da estudantada com a ciência, o conhecimento. Para Michel Foucault a Ciência ${ }^{5}$ é denominada a partir de um triedro de saberes, a saber: as ciências exatas - que se utilizam de proposições evidentes a partir de axiomas -; as ciências empíricas que são discriminadas como sendo a economia, a biologia e a linguística, tendo cada uma dessas áreas um objeto de aplicação, o trabalho, a vida e a linguagem, e por fim, a analítica da finitude.

Para a grande massa de estudantes, dentro da estrutura burguesa de ensino, a ciência tornou-se uma espécie de escola profissionalizante, como se a ciência não estivesse relacionada com a vida, tendo apenas como função preparar o estudante para uma profissão, nesse sentido assevera Benjamin:

\begin{abstract}
Aqui pode-se objetar que para a grande maioria dos estudantes, a ciência é uma escola profissional. Já que "a ciência não tem nada a ver com a vida", ela deve reger exclusivamente a vida de quem a segue. Dentre as objeções mais inocentes e mentirosas está a expectativa de que ela deve ajudar fulano ou beltrano e se prepararem para uma profissão. A profissão resulta tão pouco da ciência que esta pode até excluí-la. Pois a ciência pela sua própria essência, não admite que o pesquisador se desligue dela. ${ }^{6}$
\end{abstract}

arqueologia é uma história das condições históricas de possibilidade do saber." (Castro, E. Vocabulário de Foucault - Um percurso pelos seus temas, conceitos e autores,2009, p. 40).

4 BENJAMIN, Opus cit 1986, p.151-152.

5 Acerca desse assunto Roberto Machado afirma que "o saber constitui uma positividade mais elementar que a ciência, possuindo critérios internos de ordenação independentes dos dela e a ela anteriores; mas também porque funciona como sua condição de possibilidade, a ponto de se poder afirmar que não há ciência sem saber, enquanto o saber tem uma existência independente de sua possível transformação em saber científico." (Machado, Roberto. A Ciência e o Saber, 2007, p. 75).

6 BENJAMIN, 1986, p.152.

Kácia Natália de Barros Sousa Lima - Graduada em História pela Universidade Federal do Ceará (UFC), Mestranda em Filosofia (UECE), Brasileira, residente em Fortaleza - CE, E-mail: kacia.natalia@gmail.com 
A ciência não tolera uma solução por si mesma, pois a ciência obriga 0 pesquisador a ser sempre um professor, a compartilhar o conhecimento. É a forma como ela entroniza o poder no saber, pois conhecimento, para Benjamin se transforma, na "consciência esclarecida" do lluminismo, em posse (Erkenntnis ist ein Haben). ${ }^{7}$ Foucault, por sua vez, assevera que todos os tipos de categorias profissionais são intimadas a exercer funções policiais, em que se evidência a supremacia do poder sobre a massa. Dessa forma a grandeza revolucionária da tarefa do cientista, é fundar uma comunidade de pesquisadores no lugar de uma corporação de funcionários públicos e diplomatas, como forma o Estado. As ciências atuais foram desviadas de sua tarefa originária, como se o conhecimento fosse uma forma de poder particular, pertencente a pequenos grupos, Nas palavras de Benjamin, o papel da ciência

mostra apenas até que ponto as ciências atuais, através do desenvolvimento de seu aparato profissionalizante (e do seu know how), foram desviadas de sua origem comum, fundada na ideia do saber, a qual agora se transformou para eles em mistério, quando não em ficção ${ }^{8}$.

Tomando por base as considerações benjaminianas, Foucault sugere que devemos refletir historicamente sobre nós próprios e o nosso presente, esclarecer a contingência das formas de vida existentes e, assim, promover a possibilidade de mudá-las: "o intelectual dizia a verdade àqueles que anda não a viam e em nome daqueles que não podiam dizê-la". ${ }^{9}$ Para isso eles se utilizavam da "consciência e da eloquência". Mas segundo Foucault, os intelectuais descobrem que as massas não precisam deles para saber pois ficou constatado que a massa sabe muito bem o que afirma. Contudo a massa encontra um obstáculo para se expressar livremente diante dos mecanismos de censura que interferem ideologicamente em toda a urdidura social, com sua megamáquina de poder: "os próprios intelectuais fazem parte desse sistema de poder, a ideia de que eles são agentes da "consciência" ${ }^{10}$ e do discurso

\footnotetext{
7 BENJAMIN, Ursprung des deutschen Trauerspiels, Frankfurt am Main, Suhrkamp Verlag,1993, p. 11.

8 Idem, ibidem, 1986, p.152.

9 FOUCAULT, Microfísica do poder, Graal, 2012, p. 71.

${ }^{10}$ Contrapondo-se a esse pensamento, Benjamin alude, em seu ensaio sobre "Alexanderplatz" de Döblin à metamorfose heroica da consciência burguesa do personagem Franz Biberkopf, como estratégia de sobrevivência, ou seja, como tentativa de libertação.
} 
também faz parte desse sistema". Sobre o papel do intelectual diz Foucault: "o papel do intelectual não é mais o de se colocar "um pouco na frente ou um pouco de lado" para dizer a muda verdade de todos". ${ }^{11} \mathrm{O}$ intelectual tem de lutar igualmente contra as formas de poder que coloca o indivíduo, na ordem do saber, da verdade, da consciência e do discurso, ${ }^{12}$ ao mesmo tempo como instrumento a ser manipulado pelas relações de poder. Há muito, segundo Foucault, que a consciência como saber, foi adquirida pela massa, e que a consciência como sujeito está presa, ocupada pela burguesia. Existe, portanto, um conjunto de saberes que de modo sutil investe em uma série de redes de poder; tais investimentos serão caracterizados por Foucault de "micropoderes", os quais são exercidos ao nível mesmo do cotidiano, penetrando, transpassando e atravessando os comportamentos, se mesclando com os desejos e com os prazeres. Os micropoderes são assinalados com o surgimento da sociedade moderna em contrapartida ao declínio do poder soberano, caracterizado por essa outra expressão de poder: a disciplina. Esse é um poder ubíquo, anônimo, difuso e capilar perpassado por todo o corpo social ${ }^{13}$.

Retomando o texto de Benjamin, o que testemunhamos é uma degradação realizada com uma naturalidade brutal, de que a ciência conduz adeptos à individualidade social e a conformidade de uma vida profissional estável:

Magia e Técnica, arte e política, p. 59. Conferir também em CALLADO, Tereza. "As metamorfoses da consciência burguesa e a imagem dialética" in: Cadernos Walter Benjamin n. 04, 2010, pp. 93-106.

${ }^{11}$ FOUCAULT, "Os Intelectuais e o Poder" in:_ Microfísica do Poder. São Paulo: Graal, 2012, p. 131."Le rôle de l'intellectuel nést plus de se placer "un peu en avant ou un peu à côté" pour dire la vérité muette de tous; c'est plutôt de lutter contre les formes de pouvoir là où il en est à la fois l'objet et l' instrument: dans l'ordre du "savoir", de la "vérité", de la "conscience", du "discours". FOUCAULT, Dits et écrits (1954-1988 Editions, Paris, Gallimard, 1994.

12 "Sabe-se bem que não se tem o direito de dizer tudo, que não se pode falar de tudo em qualquer circunstância, que qualquer um enfim, não pode falar de qualquer coisa. Tabu do objeto, ditual da circunstância, direito privilegiado ou exclusivo do sujeito que fala: temos aí um jogo de três tipos de interdições que se cruzam, se reforçam ou se compensam, formando uma grade complexa que não cessa de se modificar. FOUCAULT, A ordem do discurso, São Paulo: Petrópolis.

${ }^{13}$ Foucault propõe que ao invés de conservamos uma imagem clássica do poder devemos possuir uma imagem do poder vista de baixo, ou seja, perceber o poder a partir de suas extremidades, não como algo que se possua, mas como algo que é exercido, constatando que "as relações de poder operam sobre ele [o corpo] de modo imediato; elas o investem, o marcam, o dirigem, o supliciam, submetem-no a trabalhos, obrigam-no a cerimônias, exigem-Ihe sinais" (FOUCAULT, 2010, p. 28) 
o estudantado, que não tem o status do funcionalismo público, fica sempre atrás do professorado [..] é uma correspondência semivelada da instituição acadêmica com os órgãos estatais, por cima da cabeça dos estudantes ${ }^{14}$.

De que adianta tolerar diversas teorias se não se garantir a vida que tais concepções trazem consigo, e ainda negar a existência desse abismo, consequência da ligação da Universidade com o Estado? Nesse sentido Benjamin assevera que existe uma "discrepância entre a Universidade e o Estado, no interesse de sua aptidão para o Estado e para a vida"15. Será sempre um erro seguir com exigências isoladas, seja de partidos, grupos, e entidades estudantis, se o espírito de totalidade continuar velado:

o confronto de uma universidade assim organizada é pouco nítido em relação à ciência, uma vez que esta, pela sua "aplicabilidade", simula tendências estatais imediatas ${ }^{16}$.

$\mathrm{Na}$ medida em que a universidade se direciona para a uma atividade operativa, esquecendo a formação integral (humanista) do homem, ou seja, na medida em que a universidade visa apenas a profissionalização, ela leva o estudante a perder automaticamente, a sua capacidade criativa a ser exercida dentro de uma comunidade já inexistente:

De fato, o estranhamento hostil e a incompreensão da escola perante a vida - uma vida que precisa de arte - podem ser interpretados como recusa da criação imediata, não ligado à profissão. Isso se manifesta de dentro para fora, no comportamento imaturo e escolar dos estudantes ${ }^{17}$.

As organizações estudantis, assim como o movimento estudantil, de uma maneira geral, caminham rumo a um aburguesamento completo das instituições, ou às vezes, uma tentativa de aparente solução. Os estudantes estão produzindo microcosmicamente no âmbito da Universidade, a cisão que esta cria com o todo social, desenvolvendo habilidades para o Estado e para a vida individual, para o egoísmo e o altruísmo. Segundo Benjamin, somente a dúvida radical, à crítica de base e a vida dedicada à reconstrução integral é que este espaço pode ser negado.

\footnotetext{
${ }^{14}$ BENJAMIN, Opus cit, 1986, p. 152.

${ }^{15}$ Idem, ibidem, 1986, p. 154

${ }^{16}$ BENJAMIN, Documentos de cultura, documentos de barbárie, 1986, p. 155.

17 BENJAMIN, 1986, p.155.
} 
Na verdade, a estudantada não possui uma vontade mais séria, ela é "a criança mimada e estragada" dos partidos e associações, mas é inteiramente privada da nobreza que a fazia defender a vida mais elevada. Há uma falsificação do espírito criador em espírito profissional, que tomou posse da Universidade e isolou a vida intelectual criativa, que não se enquadra na vida profissional. Acerca do papel do intelectual Michel Foucault assinala:

Parece-me que a politização de um intelectual tradicionalmente se fazia a partir de duas coisas: em primeiro lugar, sua posição de intelectual na sociedade burguesa, no sistema de produção capitalista, na ideologia que ela produz ou impõe (ser explorado, reduzido à miséria, rejeitado, "maldito", acusado de subversão, de imoralidade, etc.); em segundo lugar, seu próprio discurso enquanto revelava uma determinada verdade, descobria relações políticas onde normalmente elas não eram percebidas. Estas duas formas de politização não eram estranhas uma em relação à outra, embora não coincidissem necessariamente. ${ }^{18}$

Foucault observa a descoberta, por parte dos intelectuais, do fato de que as massas não necessitavam de sua atuação para saber. Contudo, permanecia um sistema que coibia essa consciência, tornando os intelectuais os agentes do saber, e consequentemente validando sua laboração intelectual. ${ }^{19}$ Nesse sentido, retomamos a Walter Benjamin, na medida em que ele visa uma educação voltada para eliminar a necessidade de uma liderança intelectual, uma vez que todos deveriam ter acesso à escolaridade, a partir da qual se formaria uma consciência para a existência.

A estudantada precisa desenvolver sua função criativa, transformar o que converte em questões cientificas, através de um posicionamento filosófico, em ideias que costumam despertar antes na arte e nas questões sociais. Os estudantes estão obcecados com a ideia de que precisam gozar sua juventude. Em um estilo de vida hedonista-consumista, estão vivendo um tempo que se faz de espera. Assim,

um terrível estigma pesa sobre a celebrada jovialidade das canções estudantis, sobre a nova imponência da rapaziada. É o medo do futuro, e ao mesmo tempo, um compactuar com o inevitável filisteísmo, evocado de bom grado na figura do "velho". Já que se vendeu a alma a burguesia, inclusive a

\footnotetext{
${ }^{18}$ FOUCAULT. Os intelectuais e o poder in:__ Microfísica do poder, 2012, p.130-131.

19 "Mas existe um sistema de poder que barra, proíbe, invalida esse discurso e esse saber. Poder que não se encontra somente nas instâncias superiores da censura, mas que penetra muito profundamente, muito sutilmente em toda a trama da sociedade. Os próprios intelectuais fazem parte desse sistema de poder, a ideia de que eles são agentes da "consciência" e do discurso também faz parte desse sistema." (FOUCAULT, 2012, p. 131).
} 
profissão e casamento, todo o mundo se agarra freneticamente àqueles poucos anos de liberdades burguesa. ${ }^{20}$

Portanto é preciso preencher esse tempo de espera irracional, pseudorromântico, destinado a passar o próprio tempo. Como se a vida do estudante estivesse sendo domesticada para uma vida futura de passividade, docilização e obediência ao Estado, ao Direito, à Família e finalmente ao mercado. Nesse sentido a domesticação é necessária não pelo lugar que ela ocupa - o de estudante - mas, tanto mais como preparo para o lugar que ele ocupará, a de profissional especializado. Pensarmos essa questão com Foucault significa perceber um envolvimento em uma rede de técnicas e determinações culturais que nos transformam, desenvolvendo, em nos, certas aptidões e negligenciando outras. Em outras palavras, como afirma Guacira Lopes Louro, "nos espaços reconhecidos e públicos ou nos cantos escondidos e privados, é exercida uma pedagogia, legitimando determinadas identidades [..], reprimindo e marginalizando outras" ou, como bem lembra Week, "é tecida uma rede de todos os pertencimentos sociais que abraçamos $^{21 "}$

Tomando por base as considerações acima desenvolvidas, Benjamin nos parece pessimista quanto ao papel do estudante. Relata que, não sendo possível uma experiência verdadeira nessa realidade alienada e reificada, tal experiência só será possível na luta contra esta própria realidade, em que os estudantes e trabalhadores entenderam que é parte de uma mesma classe, a classe que precisa mudar o rumo da História e o tempo de mudança é o tempo de agora (Jetztzeit), tempo kairológico na medida em que abre uma brecha no tempo cronológico, destruindo o tempo homogêneo e vazio do contínuum histórico, e, simultaneamente, tempo messiânico, que abrevia, de forma revolucionária, toda a história do sofrimento vivido pelas gerações passadas, com vistas à redenção.

\footnotetext{
${ }^{20}$ BENJAMIN, 1986, p.157.

${ }^{21}$ LOURO apud WEEKS, 2010, p. 31.
} 


\section{REFERÊNCIAS}

BENJAMIN, Walter, Ursprung des deutschen Trauerspiels, Frankfurt am Main, Suhrkamp Verlag, 1993.

BENJAMIN, Walter. Documentos de Cultura, documentos de barbárie: escritos escolhidos. Trad. br.: Celeste H. M. Ribeiro de Sousa.. et al. São Paulo: Cultrix, 1986.

CALLADO, Tereza de Castro, "As metamorfoses da consciência burguesa e a imagem dialética" in: _Cadernos Walter Benjamin n. 04, Fortaleza: Eduece, 2010, também acessível no site: www.gewebe.com.br

CASTRO, Edgardo. Vocabulário de Foucault: Um percurso pelos seus temas, conceitos e autores. Trad. br.: Ingrid Müller Xavier, revisão técnica: Walter Omar Kohan e Alfredo Veiga-Neto. Belo Horizonte: Autêntica Editora, 2009.

FOUCAULT, Michel, Dits et Écrits -1954-1988, Paris: Editions Gallimard, 1993.

FOUCAULT, Michel. "À propos de la génealogie de l'éthique: um aperçu du travail em cours". In: Dits et écrits, v. IV (1980-1988). Paris: Gallimard, 1994.

FOUCAULT, Michel. A ordem do discurso, São Paulo: Looyola, 1996.

FOUCAULT, Michel. História da Sexualidade: A vontade de Saber. Trad. Br.: Maria Thereza da Costa Albuquerque e J. A Guilhon Albuquerque. Rio de Janeiro: Edições Graal, 2010.

FOUCAULT, Michel. Microfísica do Poder. Trad. br.: Roberto Machado. $25 \underline{a}$ edição. Rio de Janeiro: Edições Graal, 2012.

LOURO, Guacira Lopes (Org.). Pedagogias da Sexualidade. Trad. br.: Tomaz Tadeu da Silva. 3 $3^{\text {a }}$ edição. Belo Horizonte: Autêntica Editora, 2010.

MACHADO, Roberto. Foucault, A Ciência e o Saber. Rio de Janeiro: Zahar, 2007.

NOVAES, Adauto (Org.) 0 silêncio dos Intelectuais, São Paulo: Compahia das Letras, 2006. 